\title{
Relation between the Sense of Strain, Social Control, Differential Associations and Juvenile Delinquency Amongst Adolescents: An Empirical Test of Robert Agnew's General Strain Theory
}

Marcin Jurczyk ( $\nabla$ marcin.jurczyk@us.edu.pl )

University of Silesia

\section{Research Article}

Keywords: General strain theory, strain theories, strain, juvenile delinquency, antisocial behavior, adolescents, crime.

Posted Date: March 7th, 2022

DOI: https://doi.org/10.21203/rs.3.rs-1252590/v1

License: (c) (i) This work is licensed under a Creative Commons Attribution 4.0 International License. Read Full License 


\section{Abstract}

The main aim of this work was to explore the existing correlation between variables in the scope of the strain (its types), social control, differential associations and illegal and anti-social behaviors demonstrated by youth offenders and high school students'. In total 266 young people were assessed in the age of 16 to 18 years old. This research involved two groups of adolescents: youth offenders and high school students. The results show that strain as the presentation of negative stimuli the most significantly predict an increase in the intensity of behavior violating legal and social norms among youth offenders. Data provide qualified support for the theory. The results could be used in the prevention of criminal behavior, therapy, social rehabilitation, and in criminal and social policy.

\section{Introduction}

Juveniles as persons committing a punishable act have become the subject of interest in many scientific disciplines, including psychology, pedagogy, criminology, sociology, and law. The issue of determinants of crime is an object of unflagging interest of researchers from various fields of science (Contreras \& Cano, 2016; Estrada, 2001; Svensson \& Ring, 2007; Wertz et al., 2016). As Armstrong (2004) suggests, youth offending is a costly societal problem that receives great attention due to concerns on many levels: It challenges our belief in childhood innocence, generates fear of lawlessness and effects of a breakdown in social integration, and questions the quality of our services and our investment in future generations.

Delinquency is a social, not a medical term. It refers to criminal behaviour, which is defined variously by different legal systems (Kurtz, 2002). As Reiss (1951) pointed out delinquency may be defined as the behavior consequent to the failure of personal and social controls to produce behavior in conformity with the norms of the social system to which legal penalties are attached. Personal control may be defined as the ability of the individual to refrain from meeting needs in ways which conflict with the norms and rules of the community. Social control may be defined as the ability of social groups or institutions to render norms or rules effective.

The juvenile can be defined as a child who has not attained a certain age at which he or she, like an adult person under the law of the land, can be held liable for his/her criminal acts. The juvenile is a child who is alleged to have committed / violated a law which declares the act or mission on the part of the child as an offence. The juvenile is a child who unlike an adult person, having not attained a prescribed age, cannot be held liable for his/her criminal act. The age criteria for being a juvenile vary from country to country, state to state (Sharma \& Kirmani, 2016). Currently in Poland, the rules of proceedings in matters related to minors are regulated by the Criminal Code, 1997 and the Act on Juvenile Delinquency Proceedings, 1982. In the light of applicable law in Poland, a minor is a person who: 1 ) is under 18 years old (in the field of preventing and combating demoralization), 2) committed a punishable act after the age of 13 and before the age of 17 (in criminal proceedings) and 3 ) is under the age of 21 (in the scope of performing the stated educational or correctional goals). 
In the last decades, what can be called social variables of youth delinquency have been studied, amongst which family and peers are highlighted (Boisvert et al., 2013; Demuth \& Brown, 2004; Ferguson et al., 2009; Griffin et al., 2000; Henry et al., 2010; Janssen et al., 2015; Labella \& Masten, 2018). Laub and Sampson (2003) have found that the social consequences of the family environment, especially low levels of parental supervision and deficient parental attachment, are strongly related to juvenile offending. Similarly, significant importance in the development of criminal behavior is attributed to siblings and a peer group (Chamberlain \& Moore, 1998; Laub \& Sampson, 2003; Leve \& Chamberlain, 2005; Scott, 1999; Wileman, 2005).

The phenomenon of juvenile delinquency as a social problem prompts to thoroughly study this phenomenon, focusing attention mainly on the factors that determine its' emergence in the context of experienced strain. Considering the phenomenon of youth delinquency, the ideal interpretative solution seems to be Robert Agnew's general strain theory (1992) presented in this paper. A similar suggestion is expressed by Kaufman et al. (2008) emphasizing that while most explanations of crime focus on micro and macro-social processes, Agnew's theory of strain complements these explanations, emphasizing the emotional and motivational psychological processes that underlie criminal behavior, thus filling an important theoretical gap.

\section{Theoretical Background}

After a period of popularity Agnew's GST met with severe criticism and a weakening of her interest due to the lack of empirical evidence (Agnew \& Passas, 1997), which consequently led to a serious revision of many courts and a re-establishment in the theoretical interpretative system, contemporary crime and other pathologies.

The nature of contemporary crimes, and especially the personality of their perpetrators, cannot be sufficiently understood in accordance with traditional sociological strain theories such as Edwin Sutherland's differential association theory, Robert Merton's theory of anomie, Travis Hirschi's social control theory of crime, David Matza's and Gresham Sykes' theory of neutralization and classical strain theories in the formulation of Albert Cohen, Richard Cloward and Lloyds Ohlin. Therefore, there is a need to refer to different paradigms and theories. Some hopes can be associated with Robert Agnew's general strain theory. As Agnew $(1992,2006,2012)$ pointed out this theory explains crime in terms of social relations in which the individual participates. It stands out from other theories, such as learning theory and control theory, due to the characteristic recognition of the types of social relationships that lead the individual's path to crime.

At the core of GST (Agnew, 1992) is the notion that negative relationships with others and negative experiences produce strain in the individual that must be managed. Instead of one general source of strain, Agnew (1992) identified three major sources: (1) the failure to achieve positively valued goals, including the disjunction between expectations and actual outcomes and the perception of what would be a fair or just outcome and actual outcomes; (2) the removal (or threat of removal) of positively valued 
stimuli that one already possesses (e.g., the death of a parent or the loss of a friend); and (3) presentation with negatively valued stimuli, such as victimization, child abuse, and negative experiences with parents, peers, police, and employers (Nivette et al., 2017). Agnew argued that such strains produce a range of negative emotions (e.g. anger, frustration, resentment, depression, anxiety) that one must somehow take corrective action to reduce; corrective actions include crime or deviance, with the behavioral solution potentially being instrumental, retaliatory, or escapist (e.g. engage in substance use to alleviate the displeasure from the negative emotions) in nature.

Agnew (1992) assumes that strain is a state resulting from the existence of negative relationships with others are, quite simply, relationships in which others are not treating the individual as he or she would like to be treated. Strain can be the result of failures in achieving positive goals and the result of the inability to legally avoid negative stressful situations. Particularly, noteworthy is the fact that Agnew modifies the range of goals pursued by individuals, not limiting himself/herself to the middle class, but also taking into account those that are promoted by the youth subculture.

Delinquent behavior in Agnew's theory is the result of pressure and occurs under the influence of negative affective states, in particular anger, which result from adverse relationships with others (Agnew, 1992). As the author emphasizes, people who experience tension may experience negative emotional reactions such as anger, fear (Agnew, 2006) and depression associated with the use of psychoactive substances. Because of the main emphasis of strain theory, the most critical emotional response is anger. Anger occurs when an individual directs his/her hostility towards others. It is the most significant emotion because it increases the sense of victimization of the individual, raises the desire for revenge and retaliation, mobilizes the individual to act, reduces control capabilities because, in part, the individual believes that others feel his anger as justified (Agnew, 1992, 2006, 2012).

One of the main terms of GST is the concept of relative deprivation referring to situations of inequality (sense of harm, disharmony), which dates back to the theory of Merton, and to which in his concept Cohen refers to the source of criminal behavior in a sense of deprivation. Agnew (1992) believes that in the case of youth, the concept of relative deprivation may refer to the subjective belief in a worse position in relation to other people, both from a closer and distant environment. Unfavorable conditions may refer to the somatic, mental, material sphere as well as life aspirations and perspectives. This problem in relation to criminal behavior (in particular youth) was raised inter alia by Agnew (1992), Agnew (1999), Agnew and White (1992), Agnew et al. (1996), Blau and Blau (1982), Braithwaite (1979), Chester (1976), Freilich et al. (2015), Groth (2003), Kramer (2000), Patterson (1991), Paternoster and Mozerolle (1994), Stiles, Liu and Kaplan (2000).

It is worth emphasizing that relative deprivation is a category similar to the concept of stress and frustration, but in the interpretation of crime it has the advantage over these widely known concepts that it refers to a more narrow class of phenomena operating in longer periods of time and is also more translatable into the term social pathology. Its actual usefulness can, however, be verified in empirical 
studies and taking into account those interpretations that also emphasize the role of personality factors in generating crime.

Prior studies have highlighted a range of strains as potential sources of criminal behaviors, including unemployment (Baron, 2008; Tittle et al., 2008), feelings of injustice (Moon et al., 2007; Pauwels \& Schils, 2016; Piazza, 2012; Smith et al., 2013), depression (Piquero \& Sealock, 2004), anger, regret, anxiety (Bao et al., 2007; Moon et al., 2009; Robertson et al., 2010), discrimination (Simons et al., 2003), bulling (Moon et al., 2011; Moon \& Morash, 2014), delinquency (Agnew, 1993; Agnew \& White, 1992; Aseltine et al., 2000; Broidy, 2001; Broidy \& Agnew, 1997; Botchkovar \& Broidy, 2010; Czerwińska-Jakimiuk, 2011a, 2011b; Drapela, 2006; Eitle, 2002; Eitle and Turner, 2003; Hoffmann and Cerbone, 1999; Hoffmann and Miller, 1998; Hoffmann and Su, 1997, 2009; Kowalczyk, 2010; Mazerolle, 1998; Paternoster and Mazerolle, 1994; Ravinder and Jo-Pei, 2012), adverse childhood experience (Simi et al., 2016; Watts and McNulty, 2013; Yun et al., 2013), using drugs (Bylica, 2010; Hoffmann et al., 2000; Slocum et al., 2005), alienation (Czerwińska-Jakimiuk, 2011c).

As DeLisi (2011) pointed out, the most exciting research questions relating to the general strain theory remain largely unexplored, and therefore unanswered, especially in relation to these connections between general tension and severe forms of criminal behavior. The application of this theory by the judiciary also appear rare, mainly in relation to the prosecution and resocialization system.

\section{Juvenile In Polish Low}

Delinquency is a legal concept used to describe diverse antisocial actions including theft, burglary, robbery, vandalism, drug use, and aggressive behaviour (Farrington 1987). In turn youth delinquency is also refers to as juvenile delinquency, juvenile offending or youth crime; and it has been defined as the participation in illegal behaviour by young people under the statutory age of majority (Siegel \& Welsh, 2005), which in most countries is 19 years old. Youth delinquent actions can range from status offenses (such as underage smoking), to property crimes and violent crimes (Abdullah et al., 2015). In turn antisocial behaviour is defined as behaviours resulting from an individual's inability to respect the rights of others. These behaviours include assault, vandalism, setting fires, theft, crime and other delinquent acts which conform to social norms (Gaik et al., 2010). As Sharma and Kirmani (2016) pointed out the juvenile is a child who is alleged to have committed /violated some law which declares the act or mission on the part of the child as an offence.

Currently in Poland, the rules of proceedings in matters related to minors are regulated by the Criminal Code 1997 and the Act on Juvenile Delinquency Proceedings 1982. In the light of applicable law in Poland, the juvenile is a person who: 1 ) is under 18 years old (in the field of preventing and combating demoralization), 2) committed a punishable act after the age of 13 and before the age of 17 (in criminal proceedings) and 3 ) is under the age of 21 (in the scope of performing the educational or correctional goals). 


\section{Methods}

Hypotheses

The theoretical basis for this research were the assumptions of Robert Agnew's General Strain Theory (1992). The main aim of this work was to explore the existing correlation between variables in the scope of the strain (its types), limiting factors (social control, differential associations) and illegal and antisocial behaviours demonstrated by the analysed youth offenders from correctional facilities for minors (research group) and high school students' anti-social behaviour (control group).

Specifically, three research questions and hypotheses has been examined:

1. Does sex and belonging to the group significantly differentiate the studied youth in the field of delinquency behavior and violating social norms?

2. Does sex and belong to the group significantly differentiate the studied youth in the field of strain (its types) and limiting factors (social control, differential associations)?

3. The relationship between delinquency behavior / violating social norms and strain (its types), limiting factors (social control, differential associations) significantly differentiates girls and boys from both studied youth groups.

H1. Sex and belonging to the group significantly differentiates the studied youth in the field of delinquency behavior and violating social norms.

H2. Sex and belonging to the group significantly differentiates the studied youth in the field of strain (its types) and limiting factors (social control, differential associations).

H3. Does the relationship between delinquency behavior / violating social norms and strain (its types), limiting factors (social control, differential associations) significantly differentiates girls and boys from both studied youth groups.

In order to respond to these research hypotheses, statistical analyses were performed using the IBM SPSS Statistics 22 package.

\section{Procedure}

The draft of this study was evaluated and approved by the Ethics Committee for Scientific Research of the Institute of Social Sciences of the Polish University Abroad in London. The project used quantitative research methods and analysis. Data was elicited using three questionnaires. In order to create conditions conducive to obtaining honest and reliable answers, the questionnaire statements were preceded by an instruction informing the respondents about the voluntary and fully anonymous nature of the research. Respondents could use the researcher's explanations in case of any doubts. The data used in the present article were collected at ages 16, 17 and 18 based on paper-and-pencil surveys that were carried out in correctional institutions for minors and in public school classrooms during the participants' 
leisure time. Informed consent for the study was obtained from the parents/legal guardians of the participating minors. The survey sessions were guided by trained study staff and lasted for 30-40 minutes on average. The data collection was performed in June 2015. Assessment of the representative quality of the group was not based on strictly statistical criteria, but on the known characteristics of the general population of Polish youth offenders. The studied population does not seem to differ from the one which was subjected to examination. Examinations were conducted using the ex-post factum procedure, which in the case of youth offenders is a difficult diagnostic process - the behavior of a person in a given situation is analyzed taking into account experiences preceding her/his act.

\section{Participants}

The method used involved questionnaires and self-report. The research group (youth offenders) were selected on the basis of their age and sex. The comparative group constituted pupils of secondary school classes (most similar to juvenile in their age and level of education) who had not violated the law (ascertained on the basis of examination using the scale of social maladjustment - self-report method). In the case of both groups, an additional criterion was the availability and readiness of respondents to participate in the study.

This research involved two groups of adolescents: youth offenders from correctional facilities for minors constituting the research group $n=133$ (52 girls and 81 boys) and high school students constituting the control group $n=133$ (66 girls and 67 boys). In total 266 adolescents were assessed. The respondents' age at the time of the research was in the range of 16 to 18 years old. The collected data allowed to conclude that the research and control group were not significantly different in terms of gender. The result of the Chi-square Test turned out to be statistically insignificant $\chi 2(2)=2.985 p=.084$. The control group is composed of equal proportions of girls and boys, while in the research group the boys are slightly predominant, but it is not statistically significant. On the basis of the empirical data obtained, it was found that the youth from the research and control group does not significantly differ in terms of age. Analysis by the Chi-square test showed no statistically significant differences $\chi 2(2)=0.019, p=.991$. The modal age for both groups was 17 years $(M a g e=17.22)$. The study was carried at the Correctional Youth Center and Shelter for Minors in Zawiercie (for girls), Falenica (for girls), Racibórz (for boys) and Pszczyna (for boys). The control group was created by students from High School No. 1 in Wloszczowa and High School named Helena Malczewska in Zawiercie.

\section{Measures}

\section{Dependent variables}

Self-Report Delinquency and Drug Use Measures was aimed at determining the type, number, and frequency of delinquent and violating social norms behaviors among the studied youth based on their own declarations. The questionnaire has been used in the research group and in the control group. In the original form used by Agnew and White (1992), the questionnaire contained 13 items and the respondents were asked about the frequency of involvement in various criminal acts in the last three 
years. Similarly to the Agnew and White studies, the frequency of a given type of behavior included in the

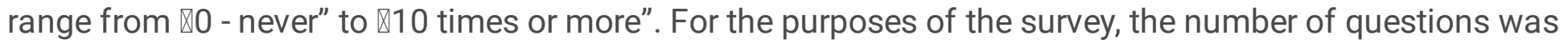
extended to a total of 22 including physical violence, robberies, burglaries, thefts, car thefts, acts of vandalism, truancy, escaping from home, drinking alcohol, alcohol abuse, taking part in beatings, selling drugs, hitting a parent, hitting a teacher, self-harm, suicide attempts, hitting someone for no particular reason, psychological torment of colleagues (ridiculing, insulting), physical bullying of weaker peers (pushing, poking, digging), tormenting animals. Cronbach's Alpha coefficient in the research group was 0.90 , in the control group was 0.79 .

Independent variables

Strain Measures: 1) Negative Life Events (items attesting to occurrence of stressful, negative life events, e.g. serious illness, death of a close person, serious illness or injury, parents' divorce, and a parent losing a job etc.); 2) Life Hassles (items concerning long-term conflicts with significant persons); 3) Negative Relations with Adults (items encompassing hostile reactions on the part of parents like: constant complaining, accusations, outbursts of anger for unimportant reasons, too rigorous upbringing, strict control); 4) Parental Fighting (items concerning verbal and physical aggression between parents); 5) Neighbourhood Problems (items attesting to a lack of a sense of security in the closest environment, including neighbourhood); 6) Unpopular with Opposite Sex (items embracing beliefs in own unattractive appearance, lack of success with the opposite sex); 7) Clothing Strain (items concerning lack of parents' consent to choose own style of clothing, of hair styles that are popular among peers); 8) Occupational Strain (items referring to belief in future problems with finding a job).

Social Control: 1) Parental Attachment (items attesting to love and attachment to parents and referring to belief that parents fulfilled the examined person's needs, praised the person, were interested in her/him); 2) Parental Permissiveness (items concerning parental permission to do what they want and "let them off easily" when they do something wrong); 3) School Attachment (items describing satisfaction with being at school and belief that completion of education will be fruitful in the future and attesting to positive relations with teachers and students). This scale is made up of two subscales: School Social Support subscale state that they get along well with teachers and their fellow classmates and the School Satisfaction subscale state that they find school satisfying, interesting, and enjoyable and that it will make a difference in their lives; 4) Peer Attachment (items concerning belief that an individual does not have (did not have) problems with making friends, is (was) liked by peers); 5) Time Spent on Homework; 6) Grades; 7) Educational Goals (items embracing aspirations and expectations related to further education).

Differential Association Factors: 1) Friends' Delinquency (items including contacts with persons/peers manifesting behaviors attesting to their social maladjustment, demoralization, and engagement in criminality and drug addiction).

Based on the analysis of the Cronbach's Alpha coefficient, it was found that three scales in the research group did not exceed the reliability threshold of 0.66 . Therefore, they were not taken into account in 
further analyzes. These scales are included the Clothing Strain scale (research group 0.604, control group 0.641), School Social Support subscale (research group 0.577, control group 0.564) and Educational Goals scale (research group 0.415 , control group 0.597 ). Based on the final analysis of all the scales whose Cronbach's Alpha coefficient reached a value above 0.66 , it was found that Cronbach's Alpha coefficient in the research group was 0.945 , while in the control group 0.965 , which proves the high reliability of the scales used.

\section{Analytical Procedure}

The draft of this study was evaluated and approved by the Ethics Committee for Scientific Research of the Institute of Social Sciences of the Polish University Abroad in London. The data used in this paper was obtained from a study designed to identify patterns of delinquency behavior among youth offenders and students in Poland, and examine the aggressive issues linked to this behavior patterns. The project used quantitative research methods and analysis. Data was elicited using three questionnaires. In order to create conditions conducive to obtaining honest and reliable answers, the questionnaire statements were preceded by an instruction informing about the voluntary and fully anonymous nature of the research. Respondents could use the researcher explanations in case of any doubts. The average time to complete the survey was 20-25 minutes in both groups of subjects. Data collection was performed in July 2015. The evaluation carried out had the authorization of the school principals, directors of correctional facilities for minors and also had parental permission. The participation of the adolescents was voluntary and anonymous, taking into consideration all ethical principles pertaining to research with a person under the current regulations. Examinations were conducted using ex-post factum procedure, which in the case of youth offenders is a difficult diagnostic process - the behavior of a person in a given situation is analyzed taking into account experiences preceding her/his act.

\section{Results}

The characteristics of the tested variables were started from descriptive statistics. The mean, standard deviation, skewness and kurtosis, minimum and maximum values were determined, and then the distribution of results and the coefficient of variation - group differentiation were checked in the ShapiroWilk test. The analysis of the obtained data was started by checking the intensity of general strain, social control, differential association and the manifestation of delinquency and antisocial behavior in both youth groups, including the sex factor.

Characteristic of general strain in the studied groups of adolescents

On the basis of the obtained results, it was found that the average result of the general strain in the research group was $82.89(S D=20.60$, kurtosis $=.21$, $\min =43$, $\max =140, V=28.85$, Shapiro-Wilk test result $=0.99, p=.16)$. In the control group, the mean general feeling of strain was $70.60(S D=17.77$, kurtosis $=.17, \min =41, \max =124, V=25.17$, Shapiro-Wilk test result $=.95, p<.01)$. The coefficient of variation ( $V$ from 20 to $40 \%$ ) indicated that the youth from the research and control group are moderately differentiated from the general feeling of strain. In addition, it was found that appurtenance to the group 
significantly differentiates youths from the general feeling of strain. The average prevalence of the general sense of strain in the research group (mean rank $=157.27$ ) is statistically higher (U Mann-Whitney $U$ test result $=-5.04, p<.01$ ) compared to the control group (mean rank $=109.73$ ). Subsequently, using the non-parametric $U$ Mann-Whitney test, the data was analyzed to determine whether appurtenance to the group significantly differentiates the studied youths of the severity of individual types of strain. The obtained results allowed to conclude that appurtenance to the group significantly differentiates the youths from both groups $(p<.01)$ terms of the average severity of six out of seven strain scales.

In the research group, statistically significant domination of strain types were found relating to: Negative Life Events $(Z=-9.72, p<.01)$; Life Hassles $(Z=-7.04, p<.01)$; Negative Relations with Adults $(Z=-4.26, p$ $<.01)$; Parental Fighting $(Z=-7.70, p<.001)$ and Neighbourhood Problems $(Z=-4.28, p<.01)$. In the control group, only one higher strain level was found regarding Occupational Strain $(Z=-0.43, p<.01)$ in comparison with the research group. However, there were no differences found between the studied groups of adolescents in terms of the intensity of the sense of strain in the area of Unpopular with Opposite $\operatorname{Sex}(Z=-2.57, p=.67)$ what can be understood that in both groups of studied youth the strain resulting from the lack of a sense of physical attractiveness occurs at a similar level.

Subsequently, the analyzes were made to obtain information on existing differences in the area of strain scales under consideration, taking into account the sex factor. For this purpose, the strength of eta-square effects $\left(\mathbb{\nabla}^{2}\right)$ has been calculated. The collected information showed the significant effect of sex and the effect of group and sex interaction in relation to the following strain scales: negative life events, negative relations with adults, neighborhood problems, and unpopular with the opposite sex.

In the first place, it was decided to check whether appurtenance to the group and the sex of the studied youth differentiate the severity of Negative Life Events scale. On the basis of the results obtained in the research group, only a statistically significant sex effect was recorded $\left(F(1.262)=13.822, p<.001 ; \mathbb{\Xi}^{2}=\right.$ .050) explaining $5 \%$ of observed variability. The strength of the recorded effect was weak, as indicated by the coefficient $\mathbb{\Xi}^{2}$. Regarding the Negative Relations with Adults scale the obtained results gave grounds for finding significant differences in all four analyzed averages. The mean prevalence of negative relations with adults among girls from the research group $(M=5.63, S D=2.29)$ in comparison with girls from the control group $(M=4.62, S D=1.75)$ is higher at the level of significance of $p=.015$. Similarly among boys from the research group $(M=6.98, S D=2.66)$ in comparison with boys from the control group $(M=5.63, S D=1.99)$ at a statistically significant level $p<.01$. The average prevalence of negative relations with adults among boys from the research group in comparison with girls from the same group is higher at the significance level $p=.01$, while in the control group the analogical difference is significant at the level $p=.01$. Based on the above results, it can be concluded that negative relations with adults are relatively more frequent among youth from the research group $(M=6.45, S D=2.60)$ compared to the control group $(M=5.13, S D=1.94)$. Higher average of the occurrence of negative relations with adults is characterized by the boys' population $(M=6.36, S D=2.46)$ from both studied groups than girls $(M=5.07$, $S D=2.06)$ from these groups. On the basis of the eta-square value, the sex effect $(F(1,262)=18.063, p$ 
$<.001, \rrbracket^{2}=.064$ ) was found to be statistically significant, accounting for $6.4 \%$ of the observed variability. Impact of the group was found at the same level explaining $6.5 \%$ of the observed volatility.

Summing up the findings to date regarding negative life events in relation to the research and control group, it can be stated that the overall result on the strain scale differentiates the studied groups only by the belonging to a peer group. The level of sense of strain associated with negative life events in the research group is significantly higher $(F(3.262)=55.251 ; R=.174 ; p<.001)$ compared to the control group. The group effect explains $17.4 \%$ of the variance. It was also found that the sex of the studied youth did not directly differentiate the level of sense of tension associated with negative life events, nor moderate the group's impact on the sense of strain.

Subsequently, the scale of Neighborhood Problems was analyzed. Analysis by pairwise comparison using the Bonferroni test showed significant differences between girls from the research and control group $(p=.002)$ and between boys from both groups $(p=.001)$. The obtained data also gave grounds for finding that in boys and girls from the research group problems in the immediate environment are more common $(M=7.20, S D=3.51)$ than among their peers from the control group $(M=5.41, S D=2.26)$. There were no significant differences between the sexes in both groups $(p>.05)$. There were only weak relationships between the sexes in the research group $(p=.078)$ and the control group $(p=.061)$. Analysis of the obtained average of neighborhood problems in the closest environment also gives grounds for stating that this phenomenon is more common in general among boys from both groups $(M=6.80, S D=$ $3.43)$ than among girls $(M=5.68, S D=2.45)$. Based on the calculated eta - square effect $\left(\nabla^{2}\right)$, a significant gender effect was found $\left(F(1.262)=6.675, p=.01, \nabla^{2}=.025\right)$, which gives grounds for finding that sex (explains $2.5 \%$ of observed variability) statistically significantly differentiates the average of neighborhood problems among the studied youth from both groups.

With regard to the next dimension of strain: Unpopular with Opposite Sex. No significant differences were found between the groups of studied youth. In the research group, no intergroup difference was found regarding sex factors between boys and girls. The pairwise comparisons used showed that the strain level associated with low physical attractiveness is significantly higher $(p=.02)$ among girls from the control group compared with boys from the same group. Based on the eta - square effect, no statistically significant sex effect was found. However, there was a weak relationship at the level of trends $(F(1.262)$ $=3.339 ; p=.069 ; \mathbb{\varpi}^{2}=.013$ ). The level of this dimension of strain is slightly (at the tendency level) higher among girls from the control group compared with girls from the research group $(p=.68)$.

Characteristic of social control in the studied groups of adolescents

The data was analyzed to determine whether there are differences between the groups of adolescents in relation to the social control variable. Based on the obtained data, it was found that the average result of the lack or low social control in the research group amounted to $99.49(S D=20.29$, kurtosis -.21 , min $=$ $57.50, \max =149, V=20.39$; Shapiro-Wilk test result $=.98, p=.09)$. In the control group, the average result of lack of social control amounted to $89.79(S D=20.07$, kurtosis $=.00$, $\min =53.50$, $\max =144, V=22.35$, Shapiro-Wilk test result $=.96, p<.01)$. The obtained data also gave grounds to claim that in the area of 
lack or low social control, boys and girls from the research group do not differ significantly between each other $(Z=-0.38, p=.70)$. Similar results were obtained relative to the control group $(Z=-0.11 ; p=0.91)$. The coefficient of variation ( $V$ from 20 to $40 \%$ ) indicated that studied youths from the research and control group are moderately differentiated from the lack of social control.

Detailed analysis of individual social control scales gave grounds to believe that appurtenance into the group (research vs control) significantly differentiates the studied youths in all social control scales ( $p$ $<.01$ ). The average of the lack or low social control in the research group is statistically higher (average rank $=152.28, Z=-3.98, p<.01$ ) compared to the control group (average rank $=114.72$ ). A detailed analysis of the average ranks of individual scales of social control showed that young people from the research group show significant statistical intensification of lack or weak social control. These relate to: Parental Attachment $(Z=-6.25, p<.01)$, Parental Permissiveness $(Z=-5.29, p<.01)$, School Attachment $(Z=-9.41, p<.01)$, Grades $(Z=-14.12, p<.01)$. In the control group, a statistically higher average was found the for scales: Peer Attachment $(Z=-2.85, p<.01)$ and Time Spent on Homework $(Z=-19.71, p$ $<.01)$.

In order to study the differentiating sex, group and interactive effect of the group and sex of the social control scales, two-factor analysis of variance was used in the intergroup scheme among the studied youth. A significant effect of sex, group and sex interaction was found on only one scale regarding School Attachment. In relation to this scale, statistically significant differences were found between girls and boys in both studied groups at the level of $p<.001$ and between girls and boys from research group $(p=.004)$. Lack of satisfaction with the fact of staying at school and the conviction that graduation will not be of any importance in the future is higher in the research group, especially among boys. The overall results also showed that the studied boys' population $(M=18.44)$ from both groups shows a higher level of this variable than girls $(M=16.08)$ from both groups combined.

Subsequently, the analyzes were made to obtain information on existing differences in the area of social control scales under consideration, taking into account the gender factor. For this purpose, the strength of eta-square effects has been calculated. The collected data showed the significant effect of sex and the effect of group and sex interaction in relation to the following social control scales: School Attachment, Grades and Time Spent on Homework.

Regarding the scale of School Attachment, only the group effect was obtained. A detailed analysis of the obtained average incidence of dissatisfaction with being at school gave grounds to conclude that youths from the research group $(M=20.59, S D=4.56)$ much more often than youths from the control group ( $M=$ $14.19 ; S D=4.60)$ is characterized by low attending school satisfaction. The group effect $(F(1.262)=$ $\left.9.296, p=.003, \mathbb{Z}^{2}=.034\right)$ explaining $3.4 \%$ of the observed variation turned out to be statistically significant.

In further analyses, attempts were made to determine the average of class repetitions in both the research and control groups. Based on the obtained data, it was established that in the research group, class repetitions is higher amongst girls $(M=2.56, S D=1.74, p<.001)$ than boys $(M=1.92, S D=1.92)$. In the 
control group, no significant differences were found between girls and boys $(p>.05)$. Based on the etasquare partial value, significant was determined sex effect $\left(F(1.262)=7.024, \mathbb{\bigotimes}^{2}=0.26 ; p<.05\right)$ responsible for $26 \%$ of the observed variation and the group effect $\left(F(1.262)=5.819, \nabla^{2}=0.22 ; p<.05\right)$ regarding $22 \%$ of the observed variation, which can be interpreted as that both sex and group membership (research vs control) significantly statistically differentiates the respondents due to the number of class repetitions.

The analysis of the data obtained, referring to the Time Spent on Homework showed that the youth of both sexes from the control group spend statistically significantly $(p<.001)$ more time on homework than youth from the research group. In the control group, girls spend more time for homework $(M=13.36, S D=$ $7.82, p=.002)$ than boys $(M=10.37 ; S D=6.11)$. The sex effect turned out to be significant $(F(1,262)=$ 8,$056 ; p=.005 ; \rrbracket^{2}=0.030$ ) explaining $3 \%$ of the observed variation, which means that sex differentiates youth because of the time spent on homework. In the research group no differences were found between boys and girls (girls $M=3.27, S D=4.24$; boys $M=2.30, S D=3.29, p>.05$ ).

Characteristic of differential association in the studied groups of adolescents

Regarding to the Friends' Delinquency variable data were obtained showing that the average result in the research group was $15.02(S D=3.97$, kurtosis $=.21, \min =5, \max =20, V=26.43$, Shapiro-Wilk test result $=.93, p<.01)$. Among girls from the research group, the average was $16.34(S D=3.36)$, while among boys $14.04(S D=4.03)$. This data gives grounds for stating that girls from the research group $(Z=-3.76, p$ $<.01)$ make contacts with friends displaying traits of social maladjustment, demoralization, involvement in crime, alcoholism and drug addiction, significantly more often than boys. In turn, in the control group, the mean severity of this variable was $8.48(S D=3.39$, kurtosis $=.21$, $\min =5$, $\max =19, V=39.98$, ShapiroWilk test result $=.88, p<.01)$. Among girls, the average was $8.00(S D=3.19)$, among boys $8.96(S D=3.54)$. These data provide grounds for stating the absence of a statistically significant difference between the two sexes ( $Z=-1.70, p=.09$ ). The coefficient of variation ( $V$ from 20 to $40 \%)$ indicates that studied youths from the research and control group are moderately differentiated in maintaining engaged contacts with a wide range of delinquent and drug-use friends. The average contact with friends displaying behaviors of social maladjustment, demoralization, involvement in crime, alcoholism and drug addiction in the research group is statistically higher (average rank $=184.26, Z=-10.79, p<.01$ ) in comparison with a control group (average rank $=82.74$ ). Also, the data suggested that the differences between the groups are significant for both sexes was also obtained $(p<.001)$. Boys from the research group significantly more often than boys from the control group are characterized by maintaining contacts with friends violating legal and social norms. A similar situation was found between girls from the research and control group. Based on the eta coefficient, the interaction of group and gender was found $(F(1.262)=$ $15.898, p<.001, \nabla^{2}=.057$ ), which accounts for $5.7 \%$ of the observed variation.

Characteristics of delinquent behavior and violating social norms in the studied groups of adolescents

Based on the data, it was found that the average result of delinquent behavior in the research group amounted to $94.67(S D=46.80)$. Among girls from the research group, the average result of delinquent behaviors was $106.54(S D=47.82)$, while among boys $87.05(S D=44.76)$. In the control group, the 
average result of antisocial behavior was $13.30(S D=16.34)$, among girls $7.18(S D=7.24)$, and boys $19.33(S D=20.20)$. The empirical data collected on manifestations of criminal behavior and violating social norms in the research group and violating social norms in the control group unambiguously gave grounds for stating that belonging to the group significantly differentiates the persons examined in relation to the antisocial behaviors they undertake. The average of behaviors that violate legal and social norms $(Z=-13.29, p<.01)$ is statistically higher in the criterion group. In addition, it was found that in the intensity of antisocial behavior undertaken, boys and girls from the research group differ significantly. The girls from the research group, compared to the boys from this group, are characterized by a significantly higher average of delinquent behaviors $(Z=-2.32, p<.05)$. In the control group, boys had a higher average of behavior that violates social norms than girls $(Z=-4.42, p<.01)$.

In order to check the existing differences between manifestations of antisocial behavior between the studied groups of adolescents, the Mann-Whitney $U$ test has been used. The general results regarding the average ranks of behavior in both groups of subjects showed the existence of statistically significant differences in all forms of antisocial behavior with their significant advantage in the research group. These behaviors include: participation in a physical violence $(Z=-11.52, p<.01)$, participation in the robbery $(Z=-10.33, p<.01)$, theft of small items up to $\$ 20(Z=-13.00, p<.01)$, stealing valuable things, e.g. cars, jewellery $(Z=-12.57, p<.01)$, burglary $(Z=-10.62, p<.01)$, acts of vandalism $(Z=-11.93, p$ $<.01)$, staying out of school $(Z=-8.62, p<.01)$, escape from home $(Z=-10.08, p<.01)$, drinking alcohol $(Z$ $=-7.49, p<.01)$, using marijuana $(Z=-11.87, p<.01)$, using LSD, amphetamine, heroin $(Z=-11.18, p<.01)$, participation in assault $(Z=-12.70, p<.01)$, selling drugs $(Z=-9.90, p<.01)$, hitting of a teacher $(Z=-5.56$, $p<.01)$, parental abuse $(Z=-4.24, p<.01)$, self-injurious behavior $(Z=-8.34, p<.01)$, suicide attempts $(Z=$ $-7.09, p<.01)$, hitting someone without a specific reason $(Z=-8.01, p<.01)$, psychological abuse of weaker colleagues $(Z=-8.63, p<.01)$, physical abuse of weaker colleagues $(Z=-8.35, p<.01)$, animal abuse $(Z=-4.67, p<.01)$, scaring others with weapons or other sharp tools $(Z=-8.55, p<.01)$.

The above data allowed to confirmed that sex and appurtenance to the group significantly differentiates studied youth in the field of behaviors that violate legal and social norms. The obtained empirical data confirmed a statistically significant difference $(p<.001)$ in the occurrence of delinquency behavior and violating social norms in the studied groups, with the prevalence of their occurrence in the research group.

Correlations among strain, social control, differential association, and youth delinquency

In the further course of the research, attempts were made to determine the existing relationships between the represented general sense of strain (and its types), social control, differential association and behaviors violating legal and social order in the research group and behaviors violating social norms in the control group. For this purpose, the analysis of R-Spearman's correlation coefficients was used. The analysis of the results obtained, included both groups of studied youth, gave grounds for establishing no significant correlations between the general sense of strain, social control and behaviors violating legal and social norms in the research group and behaviors violating social norms in the control group (Table 1 here). 
TABLE I. Correlations among General Strain, Social Control, Differential Association, and Youth Delinquency

In addition, the obtained results gave the basis for the statement that in both groups of the studied youth maintaining contact with friends who exhibit behaviors indicating social maladjustment, demoralization, involvement in crime, alcoholism and drug addiction at a statistically significant level $(p<.01)$ correlates with behaviors violating legal and social norms in both study groups.

The further analyzes show correlations related to individual strain scales, social control and differential association. The obtained results are shown in Table 2.

In the light of the presented results regarding strain measure, it was found that the greater the severity of negative life events in adolescents' lives, the more likely they are to take exhibit behaviors that violates legal and social norms $(R=.23, p<.01)$. In the area of social control measure, data was obtained suggesting that the lower intensity of satisfactory peer attachment $(R=-.18, p<.05)$ and the low amount of time spent on homework $(R=-.24, p<.01)$ corresponds to the greater intensity of undertaken behavior violating legal and social norms. Similar results were obtained relative to the differential association measure, suggested that increased contact with friends displaying behaviors demonstrating social maladjustment, demoralization, involvement in crime, alcoholism and drug addiction, the more likely the research group are exhibit behaviors violating legal and social norms $(R=.49, p<.01)$.

In the control group, correlations were obtained that concluded the higher the severity of negative relationships with adults (teachers, parents), the higher the likelihood among students to engage in behavior that violates social norms $(R=.23, p<.01)$. In the scope of the social control measure, it was found that there was lower school attachment. Similarly there was lower belief that school completion would pay off in the future. This was accompanied by an average higher level of involvement in behavior violating social norms $(R=-.18, p<.05)$. As in the research group, among students from the control group, the correlation obtained gave grounds to believe that the higher the level of contacts with friends displaying behaviors demonstrating social maladjustment, demoralization, involvement in crime, alcoholism and drug addiction in students' lives, the higher the likelihood of involvement in behavior violating social norms $(R=.34, p<.01)$.

Analysis of correlations between variables in the regression model

Similarly to Agnew and White research (1992), stepwise regression analysis was performed, in which delinquent behavior and antisocial were determined as the dependent variable. The variables examined included sex, age, group, strain scales, social control scales and differential association scale. The use of stepwise regression analysis in relation to the research group allowed (after elimination of insignificant predictors) to introduce only independent variables into the model that significantly predict the dependent variable. The obtained results are presented in Table 3. 
In the research group, after adjusting $R^{2}=0.172$, the model turned out to be relevant for only one predictor: Friends' Delinquency (Beta $=.422$ ). The model proved to be well suited to the data $(F(1,131)=$ $28,248 ; p<.001)$. This variable explains $17.2 \%$ of the variance of the dependent variable among youth from the research group. The correlation between variables is strong and positive. Based on the obtained regression result, it can be stated that only one predictor most significantly predicts retaining violating legal and social norms among adolescents from research group. This justifies the conclusion that the increase in contact with friends displaying behaviors indicating social maladjustment, demoralization, and involvement in crime, alcoholism and drug addiction predicts an increase in the intensity of behaviors that violate legal and social norms among adolescents from the research group. The above correlation can be understood as significant, which fully confirms Sutherland's thesis that criminal behavior is a learned behavior, and the learning of criminal behavior itself occurs in the course of interaction with other people in the communicative process and that a substantial part of learning criminal behavior takes place in within primary groups.

\section{Conclusions}

It seems important to refer to research results obtained by Agnew and White (1992) based on which the authors concluded that the most important predictors of youth crime are: negative life events (Beta $=0.14$; $p<.01)$, life hassles (Beta $=0.08 ; p<.01)$ and negative relations with adults (Beta $=0.06 ; p<.01)$. In turn, E. Czerwińska-Jakimiuk (2011) stated that the most important predictors of youth crime are: negative life events (Beta $=0.439 ; p<.00)$; low level of aspirations related to further education - educational goals (Beta $=0.202 ; p<.00)$; life hassles (Beta $=0.196 ; p<.04)$. In the author's own study $(2015)$ only one predictor of youth crime turned out to be the most important: friends' delinquency (Beta $=0.422 ; p<.001$ ).

It seems justified to draw attention to the changes taking place in contemporary social reality. The regression model contained a predictor (friends' delinquency), which in previous American and Polish studies did not show significant conditioning of the dependent variable. So, one can conclude that there is a significant change in the factors involved in changing the behavior of adolescents. The justification of the above situation seems to be the changing social reality within which the growth of social pathologies are constantly marked, i.e. phenomena such as crime, alcoholism and drug addiction among adolescents and adults. It should be noted that criminal environments are not exclusively confined to peer groups. Parents who have presented a history of criminality and addiction to psychoactive substances also constitute a significant environmental factor. As Agnew and Bylica (2011) pointed out many individuals are not involved in crime because they are under direct parental control. They are surrounded by other people who present solid boundaries that prevent unacceptable behavior, closely monitor behavior and consistently react appropriately to rule violations. They can be parents, teachers, neighbors, employers and the police. Individuals refrain from criminal behavior also because of strong emotional ties with conventional others (parents, spouses, teachers). They do not want to cause hurt and endanger their bonds. They refrain from crime because they have made significant investments in conventional activities, such as school or work; they have good grades or a satisfying job. 
A holistic approach to educational activities focused on the immediate environment of young people should primarily revolve around issues related to risk factors. Preventive and educational activities in relation to criminal youth should be designed to emplant that the primary environment to which the minor will return sooner or later. This should be covered by preventive measures aimed at changing the situation of the family and their awareness of the consequences and causes of an improper educational style. When undertaking measures to prevent the escalation of social maladjustment of young people, careful observation and disclosure of pathological factors are needed. Particular attention should be paid to the family environment because its operation is fundamental in the process of socialization. The family environment should be observed not only because of faulty parental functions but also for the education of parents and others carers. Social rehabilitation activities should take into account educational and therapeutic interventions aimed at improving family ties and thus exercising social control. These activities should include the education of parents and guardians, i.e. pre-emptive actions oscillating around social education and training in various areas of youth life. It is important to forecast the fate of the minor and to teach young people how to develop an awareness of their emotions, how to control them, along with the development of interpersonal skills and assertiveness.

Social rehabilitation and preventive measures should also take into account the organizational and substantive cooperation of the school with the family environment of the youth, identification of risk factors in the family and school. Places of support for the youth regarding alcohol, drugs, violence, and aggression in the school and family environment are an essential auxiliary. GST is not a simple concept because in essence it is an unspectacular organic work. It postulates creating openness in communication and building trust relations with young adults. Even more detrimental is that, it obliges us to raise difficult issues, often saturated with untampered anger. Prophylaxis consists on the one hand in constructing harmonious situations, free from affective emotions, whilst conversely responding and resolving situations saturated with these emotions. The collected results of conducted research and analyzes, in addition to a lot of information that may contribute to advancing our knowledge of juvenile delinquency, may also result in further insight on youth work being the basis for further preventive activities related to juvenile delinquency, but also programs based on early intervention focused on families and schools.

\section{Declarations}

\section{Author Disclosure Statement}

The author declared no potential conflicts of interest with respect to the research, authorship, and/or publication of this article. All experiments were performed in accordance with relevant guidelines and regulations. Informed consent was obtained from all subjects and/or their legal guardian(s).

\section{Data availability}

The datasets used and/or analysed during the current study available from the corresponding author on reasonable request. 


\section{References}

1. Abdullah, H., Ortega, A., Ahmad, N., Ghazali, S. (2015). Aggressive and Delinquent Behavior among High Risk Youth in Malaysia. Asian Social Science, 11, 62-73.

2. Agnew, R. (1992). Foundation for a general strain theory of crime and delinquency. Criminology, 30, 47-87.

3. Agnew, R. (1993). Why do they do it? An examination of the intervening mechanisms between social control variables and delinquency. Journal of Research in Crime and Delinquency, 30, 245-266.

4. Agnew, R. (1999). A General strain theory of community differences in crime rates. Journal of Research in Crime, 36, 123-155.

5. Agnew, R. (2006). Pressured into crime: An overview of general strain theory. New York: Oxford University Press.

6. Agnew, R. (2012). Reflection on: a revised strain theory of delinquency. Social Forces, 91, 33-38.

7. Agnew, R., Bylica, J. (2011). GST - idea oraz rekomendacje dla profilaktyki zachowań przestępczych. Resocjalizacja Polska. Polish Journal of Social Rehabilitation, 2, 233-255.

8. Agnew, R., Cullen, F. T., Burton, V. S., Evans, T. D., Dunaway, R. G. (1996). A new test of classic strain theory. Justice Quarterly, 13, 681-704.

9. Agnew, R., Passas, N. (1997). The future of anomie theory. Boston: Northeastern University Press.

10. Agnew, R., White, R. H. (1992). An empirical test of general strain theory. Criminology, 30, 475-500.

11. Armstrong, D. (2004). A Risky Business? Research, Policy, Governmentality and Youth Offending. Youth Justice, 4, 100-16.

12. Aseltine, R. H., Gore, S., Gordon, J. (2000). Life stress, anger, anxiety, and delinquency: An empirical test of general strain theory. Journal of Health and Social Behavior, 41, 256-275.

13. Baron, R., Kenny, D. (1986). The moderator - mediator variable distinction in the social psychology research: Conceptual strategic and statistical considerations. Journal of Personality and Social Psychology, 51, 1173-1182.

14. Blau, J., Blau, P. (1982). The cost of inequality: metropolitan structure and violent crime. American Sociological Review, 47, 114-129.

15. Boisvert, D., Boutwell, B. B., Vaske, J., Newsome, J. (2013). Genetic and Environmental Overlap Between Delinquent Peer Association and Delinquency in Adolescence. Criminal Justice and Behavior, 41, 58-74.

16. Botchkovar, E., Broidy, L. (2010). Accumulated strain, negative emotions and crime: a test of general strain theory in Russia. Crime and Delinquency, 59, 837-860.

17. Braithwaite, J. (1979). Inequality, crime and public policy. London: Routledge and Kegan Paul Ltd.

18. Broidy, L. M. (2001). A test of general strain theory. Criminology, 39, 9-36.

19. Broidy, L. M., Agnew, R. (1997). Gender and crime: a general strain theory perspective. Journal of Research in Crime and Delinquency, 34, 275-306. 
20. Bylica, J. (2010). Harmonizując napięcie. Nowe spojrzenie w profilaktyce uzależnień [Harmonizing the strain. A new look at addiction prevention]. Kraków: Wydawnictwo Uniwersytetu Jagiellońskiego.

21. Chamberlain, P., Moore, K. (1998). A Clinical Model for Parenting Juvenile Offenders: a Comparison of Group Care versus Family Care. Clinical Child Psychology and Psychiatry, 3, 375-86.

22. Chester, C. R. (1976). Perceived relative deprivation as a cause of property crime. Crime and Delinquency, 22, 17-30.

23. Contreras, L., Cano, M. C. (2016). Child-to-parent violence: The role of exposure to violence and its relationship to social-cognitive processing. European Journal of Psychology Applied to Legal Context, 8, 43-50.

24. Czerwińska-Jakimiuk, E (2011a). Przestępczość młodocianych. Interpretacja zjawiska w świetle ogólnej teorii napięcia Roberta Agnew [Youth Crime. Interpretation of the Phenomenon in Light of Robert Agnew's General Strain Theory]. Kraków: Wydawnictwo Naukowe UP.

25. Czerwińska-Jakimiuk, E (2011b). Youth crime. An empirical test of Robert Agnew's general strain theory. Problems of Forensic Sciences, 86, 114-126.

26. Czerwińska-Jakimiuk, E (2011c). Senses of strain and alienation in a group of young adult offenders. Research findings. Problems of Forensic Sciences, 87, 228-238.

27. DeLisi, M. (2011). How general is general strain theory? Journal of Criminal Justice, 39, 1-2.

28. Demuth, S., Brown, S. L. (2004). Family Structure, Family Processes, and Adolescent Delinquency: The Significance of Parental Absence Versus Parental Gender. Journal of Research in Crime and Delinquency, 41, 58-81.

29. Drapela, L. A. (2006). The effect of negative emotion on licit and illicit drug use among high school dropouts: An empirical test of general strain theory. Journal of Youth and Adolescence, 35, 755-770.

30. Eitle, D. J. (2002). Exploring a source of deviance-producing strain for females: Perceived discrimination and general strain theory. Journal of Criminal Justice, 30, 95-111.

31. Eitle, D. J., Turner, R. J. (2003). Stress exposure, race, and young adult crime. Sociological Quarterly, 44, 243-269.

32. Estrada, F. (2001). Juvenile Violence as a Social Problem. The British Journal of Criminology, 41, 639-55.

33. Ferguson, C. J., Miguel, C. S., Hartley, R. D. (2009). A Multivariate Analysis of Youth Violence and Aggression: The Influence of Family, Peers, Depression, and Media Violence. The Journal of Pediatrics, 55, 904-908.

34. Freilich, J. D., Adamczyk, A., Chermak, S. M., Perkin, W. (2015). Investigating the Applicability of Macro-Level Criminology Theory to Terrorism: A Country-Level Analysis. Journal of Quantitative Criminology, 31, 383-411.

35. Gaik, L. P., Abdullaha, M. C., Habibah, E., Uli, J. (2010). Development of Antisocial Behaviour. Procedia Social and Behavioral Sciences, 7, 383-388. 
36. Griffın, K. W., Botvin, G. J., Scheier, L. M., Diaz, T., Miller, N. L. (2000). Parenting practices as predictors of substance use, delinquency, and aggression among urban minority youth: Moderating effects of family structure and gender. Psychology of Addictive Behaviors, 14, 174-184.

37. Groth, J. (2003). Rozwój moralny a radzenie sobie ze stresem u nieletnich przestępców [Moral development and coping with stress amongst juvenile offenders]. Poznań: Bogucki Wydawnictwo Naukowe.

38. Henry, D. B., Tolan, P. H., Gorman-Smith, D. (2010). Longitudinal Family and Peer Group Effects on Violence and Nonviolent Delinquency. Journal of Clinical Child \& Adolescent Psychology, 30, 172186.

39. Hoffmann, J. P., Cerbone, F. G. (1999). Stressful life events and delinquency escalation in early adolescence. Criminology, 37, 343-373.

40. Hoffmann, J. P., Cerbone, F. G., Su, S. S. (2000). A Growth Curve Analysis of Stress and Adolescent Drug Use. Substance Use and Misuse, 35, 687-716.

41. Hoffmann, J. P., Miller, A. S. (1998). A latent variable analysis of general strain theory. Journal of Quantitative Criminology, 14, 83-110.

42. Hoffmann, J. P., Su, S. S. (1997). The Conditional Effects of Stress on Delinquency and Drug Use: A Strain Theory Assessment of Sex Differences. Journal of Research in Crime and Delinquency, 34, 4678.

43. Hoffmann, J. P., Su, S. S. (2009). Stressful Life Events and Adolescent Substance Use and Depression: Conditional and Gender Differentiated Effects. Substance Use and Misuse, 33, 22192262.

44. Janssen, H. J., Eichelsheim, V. I., Deković, M., Bruinsma, G. J. N. (2015). How is parenting related to adolescent delinquency? A between and within person analysis of the mediating role of self-control, delinquent attitudes, peer delinquency, and time spent in criminogenic settings. European Journal of Criminology, 13, 169-194.

45. Kaufman, J. M., Cesar, J. R., Thaxton, S., Agnew, R. (2008). A general strain theory of racial differences in criminal offending. The Australian and New Zealand Journal of Criminology, 41, 421437.

46. Kowalczyk, M. H. (2010). Zabójcy i mordercy. Czynniki ryzyka i możliwości oddziaływań resocjalizacyjnych [Assassins and murderers. Risk factors and possibilities of social rehabilitation interactions]. Kraków: Wydawnictwo Impuls.

47. Kramer, R. C. (2000). Poverty, inequality and youth violence. Annals of America Academy of Political and Social Science, 567, 123-139.

48. Kurtz, A. (2002). What works for delinquency? The effectiveness of interventions for teenage offending behaviour. The Journal of Forensic Psychiatry, 13, 671-692.

49. Labella, M. H., Masten, A. S. (2018). Family influences on the development of aggression and violence. Current Opinion in Psychology, 19, 11-16. 
50. Laub, J., Sampson, R. (2003). Shared beginnings, divergent lives. Cambridge: Harvard University Press.

51. Leve, L. D., Chamberlain, P. (2005). Association with Delinquent Peers: Intervention Effects for Youth in the Juvenile Justice System. The Journal of Abnormal Clinical Psychology, 33, 339-347.

52. Lieven, P., Schils, N. (2016). Differential Online Exposure to Extremist Content and Political Violence: Testing the Relative Strength of Social Learning and Competing Perspectives. Terrorism and Political Violence, 28, 1-29.

53. Mazerolle, P. (1998). Gender, general strain, and delinquency: An empirical examination. Justice Quarterly, 15, 65-91.

54. Moon, B., Blurton, D., McCluskey, J. D. (2007). General Strain Theory and Delinquency: Focusing on the Influences of Key Strain Characteristics on Delinquency. Crime \& Delinquency, 54, 582-613.

55. Moon, B., Hwang, H. W., McCluskey, J. D. (2011). Causes of School Bullying: Empirical Test of a General Theory of Crime. Differential Association Theory and General Strain Theory. Crime \& Delinquency, 57, 849-877.

56. Moon, B., Morash, M. (2014). Gender and General Strain Theory. A Comparison of Strains, Mediating, and Moderating Effects Explaining Three Types of Delinquency. Youth and Society 49, 484-504.

57. Moon, B., Morash, M., McCluskey, C. P., Hwang, H. W. (2009). A comprehensive test of general strain theory: Key strains, situational-and trait-based negative emotions, conditioning factors, and delinquency. Journal of Research in Crime and Delinquency, 46, 182-212.

58. Nivette, A., Eisner, M., Ribeaud, D. (2017). Developmental Predictors of Violent Extremist Attitudes: A Test of General Strain Theory. Journal of Research in Crime and Delinquency, 54, 755-790.

59. Paternoster, R., Mazerolle, P. (1994). General strain theory and delinquency: a replication and extension. Journal of Research in Crime and Delinquency, 31, 235-263.

60. Patterson, W. (1991). Poverty, income inequality and community crime rates. Criminology, 29, 755776.

61. Pauwels, L., Schils, N. (2016). Differential Online Exposure to Extremist Content and Political Violence: Testing the Relative Strength of Social Learning and Competing Perspectives. Terrorism and Political Violence, 28, 1-29.

62. Piazza, J. A. (2012). Types of Minority Discrimination and Terrorism. Conflict Management and Peace Science, 29, 521-46.

63. Piquero, N. L., Sealock, M. D. (2004). Gender and general strain theory: A preliminary test of Broidy and Agnew's gender/GST hypotheses. Justice Quarterly, 21, 125-157.

64. Ravinder, B., Jo-Pei, T. (2012). Foster youth and crime: Employing general strain theory to promote understanding. Journal of Criminal Justice, 40, 212-220.

65. Reiss, A. J. (1951). Delinquency as the Failure of Personal and Social Controls. American Sociological Review, 16, 196-207. 
66. Robertson, A. R., Stein, J. A., Schaefer-Rohleder, L. (2010). Effects of Hurricane Katrina and other adverse life events on adolescent female offenders. A test of general strain theory. Journal of Research in Crime and Delinquency, 47, 469-495.

67. Scott, C. L. (1999). Juvenile Violence. Psychiatric Clinics of North America, 22, 71-83.

68. Sharma, D., Kirmani, M. N. (2016). Aggression among Juvenile and Non-Juvenile Delinquents: An Empirical Analysis. International Journal of Humanities and Social Science Studies, 3, 213-219.

69. Sharma, P., Kirmani, M. N. (2016). Aggression among Juvenile and Non-Juvenile Delinquents: An Empirical Analysis. International Journal of Humanities \& Social Science Studies, 3, 213-219.

70. Siegel, LJ, Welsh, BC (2005). Juvenile Delinquency: The core. (Belmont, Wadsworth, CA.)

71. Simi, P., Sporer, K., Bubolz, B. F. (2016). Narratives of Childhood Adversity and Adolescent Misconduct as Precursors to Violent Extremism: A Life-Course Criminological Approach. Journal of Research in Crime and Delinquency, 53, 536-63.

72. Simons, R. L., Chen, Y. F., Stewart, E. A., Brody, G. H. (2003). Incidents of discrimination and risk for delinquency: A longitudinal test of strain theory with an African American sample. Justice Quarterly, 20, 827-854.

73. Slocum, L. A., Simpson, S. S., Smith, D. A. (2005). Strained lives and crime: Examining intraindividual variation in strain and offending in a sample of incarcerated women. Criminology, 43, 1067-1110.

74. Smith, T. R., Kudlac, C., Fera, A. G. (2013). Deviant reactions to the college pressure cooker. A test of general strain theory on undergraduate students in the United States. International Journal of Criminal Justice Sciences, 8, 88-104.

75. Stiles, LB, Liu, X and Kaplan, HB (2000). Relative deprivation and deviant adaptations: the mediating effect of negative self-feelings. Journal of Research in Crime and Delinquency, 37, 64-90.

76. Svensson, R., Ring, J. (2007). Trends in Self-Reported Youth Crime and Victimization in Sweden, 1995-2005. Journal of Scandinavian Studies in Criminology and Crime Prevention, 8, 185-209.

77. Tittle, C. R., Broidy, L. M., Gertz, M. G. (2008). Strain, Crime, and Contingencies. Justice Quarterly, 25, 283-312.

78. Wan-Ning, B., Haas, A., Yijun, P. (2007). Life Strain, Coping, and Delinquency in the People's Republic of China: An Empirical Test of General Strain Theory from a Matching Perspective in Social Support. International Journal of Offender Therapy and Comparative Criminology, 51, 9-24.

79. Watts, S. J., McNulty, T. L. (2013). Childhood Abuse and Criminal Behavior. Testing a General Strain Theory Model. Journal of Interpersonal Violence, 28, 3023-3040.

80. Wertz, J., Nottingham, K., Agnew-Blais, J., Matthews, T., Pariante, C. M., Moffitt, T. E., Arseneault, L (2016). Parental monitoring and knowledge: Testing bidirectional associations with youths' antisocial behavior. Development and Psychopathology, 28, 623-638.

81. Wileman, B. (2005). The recidivist juvenile offender, primary group deficiency and recidivism into adulthood: A prospective study, 1980-2002. Melbourne: Monash University Press. 
82. Yun, M., Kim, E., Morris, R. (2013). Gendered pathways to delinquency: An examination of general strain theory among South Korean youth. Youth Violence and Juvenile Justice, 12, 268-292.

\section{Tables}

TABLE I. Correlations among General Strain, Social Control, Differential Association, and Youth Delinquency

\begin{tabular}{|c|c|c|c|c|}
\hline \multirow{4}{*}{ Variables } & \multicolumn{2}{|c|}{ Research Group } & \multicolumn{2}{|c|}{ Control Group } \\
\hline & \multicolumn{2}{|c|}{$N=133$} & \multicolumn{2}{|c|}{$N=133$} \\
\hline & \multicolumn{2}{|c|}{$\begin{array}{l}\text { Delinquency behavior and antisocial behavior } \\
\text { violates social norms }\end{array}$} & \multicolumn{2}{|c|}{$\begin{array}{l}\text { Antisocial behavior violates } \\
\text { social norms }\end{array}$} \\
\hline & $\mathrm{R}$ & Sig. & $\mathrm{R}$ & Sig. \\
\hline General Strain & 0,05 & 0,56 & 0,03 & 0,73 \\
\hline Social Control & $-0,06$ & 0,52 & 0,03 & 0,76 \\
\hline $\begin{array}{l}\text { Differential } \\
\text { Association }\end{array}$ & 0,49 & $<0,01^{*}$ & 0,33 & $<0,01^{*}$ \\
\hline
\end{tabular}

$R$-Value of the R-Spearman coefficient; ${ }^{*}$ Correlation is significant at the 0.01level (2-sided); $\mathrm{N}$ - number of respondents

Source: own research

TABLE 2. Detailed Correlations among General Strain, Social Control, Differential Association and Unrespecting Legal/Social Norms in Studied Groups of Adolescents 


\begin{tabular}{|c|c|c|c|c|}
\hline \multirow{4}{*}{ Variables } & \multirow{2}{*}{\multicolumn{2}{|c|}{$\begin{array}{l}\text { Research Group } \\
N=133\end{array}$}} & \multirow{2}{*}{\multicolumn{2}{|c|}{$\begin{array}{l}\text { Control Group } \\
N=133\end{array}$}} \\
\hline & & & & \\
\hline & \multicolumn{2}{|c|}{$\begin{array}{l}\text { Delinquency behavior and antisocial behavior } \\
\text { violates social norms }\end{array}$} & \multicolumn{2}{|c|}{$\begin{array}{l}\text { Antisocial behavior violates } \\
\text { social norms }\end{array}$} \\
\hline & $\mathrm{R}$ & Sig, & $\mathrm{R}$ & Sig. \\
\hline \multicolumn{5}{|l|}{ Strain Measures } \\
\hline $\begin{array}{l}\text { Negative Life } \\
\text { Events }\end{array}$ & 0,23 & $<0,01$ ** & 0,10 & 0,25 \\
\hline Life Hassles & 0,00 & 0,96 & 0,08 & 0,39 \\
\hline $\begin{array}{l}\text { Negative Relations } \\
\text { with Adults }\end{array}$ & 0,03 & 0,71 & 0,23 & $<0,01^{\star \star}$ \\
\hline Parental Fighting & 0,12 & 0,16 & 0,12 & 0,16 \\
\hline $\begin{array}{l}\text { Neighborhood } \\
\text { Problems }\end{array}$ & 0,04 & 0,62 & 0,17 & 0,06 \\
\hline $\begin{array}{l}\text { Unpopular with } \\
\text { Opposite Sex }\end{array}$ & $-0,05$ & 0,56 & $-0,16$ & 0,06 \\
\hline Occupational Strain & 0,06 & 0,48 & $-0,04$ & 0,65 \\
\hline \multicolumn{5}{|c|}{ Social Control Measures } \\
\hline $\begin{array}{l}\text { Parental } \\
\text { Attachment }\end{array}$ & $-0,05$ & 0,55 & 0,02 & 0,78 \\
\hline $\begin{array}{l}\text { Parental } \\
\text { Permissiveness }\end{array}$ & $-0,08$ & 0,34 & 0,05 & 0,57 \\
\hline School Attachment & 0,14 & 0,11 & $-0,18$ & $<0,04^{\star}$ \\
\hline Peer Attachment & $-0,18$ & $<0,05^{\star}$ & $-0,02$ & 0,80 \\
\hline $\begin{array}{l}\text { Time Spent on } \\
\text { Homework }\end{array}$ & $-0,24$ & $0,01^{*}$ & $-0,16$ & 0,07 \\
\hline Grades & 0,06 & 0,48 & 0,02 & 0,86 \\
\hline \multicolumn{5}{|c|}{ Differential Association Measure } \\
\hline $\begin{array}{l}\text { Friends' } \\
\text { Delinquency }\end{array}$ & 0,49 & $<0,01^{\star \star}$ & 0,34 & $<0,01^{\star \star}$ \\
\hline $\begin{array}{l}\mathrm{R}-\text { Value of the R-Sp€ } \\
\star \star \text { Correlation is signif }\end{array}$ & $\begin{array}{l}\operatorname{man} c \\
\text { ant at }\end{array}$ & $\begin{array}{l}\text { prelation is significant at th } \\
\text { (2-sided). }\end{array}$ & .05 le & ided); \\
\hline
\end{tabular}

Source: own research 
TABLE 3. Regression Results - Coefficients

\begin{tabular}{|lllll|}
\hline & \multicolumn{3}{l}{ Delinquency behavior and antisocial behavior violates social norms } \\
\cline { 2 - 4 } & \multicolumn{2}{l}{ Unstandardized coefficients } & \multicolumn{2}{c|}{ Standardized coefficients } \\
\cline { 2 - 4 } Variables & B & Std. error & Beta & Sig. \\
\hline (Constant) & 16,461 & 15,048 & &, 276 \\
\hline Friends' Delinquency & 3,627 &, 682 &, 422 & $\mathbf{0 , 0 0 1}$ \\
\hline
\end{tabular}

B - Unstandardized regression coefficient; Beta ( $\beta$ ) - standardized regression coefficient.

Source: own research 